www.jmscr.igmpublication.org

Impact Factor 5.84

Index Copernicus Value: 83.27

ISSN (e)-2347-176x ISSN (p) 2455-0450

crossref DOI: _https://dx.doi.org/10.18535/jmscr/v5i3.158

Journal Of Medical Science And Clinical Research

IGM Publication

An Official Publication of IGM Publication

\title{
A Prospective Randomized Study to Compare and Evaluate King Vision Video Laryngoscope and McCoy Laryngoscope as Intubating Devices in Adult Patients
}

\author{
Authors \\ Dr Sarfaraz Ahmad ${ }^{1}$, Dr Qazi Ehsan Ali ${ }^{2}$, Dr Md Kashif Jamal ${ }^{3}$, Dr Shadab Kamal ${ }^{4}$, \\ Dr Krochi Pal ${ }^{5}$ \\ ${ }^{1 \& 3} \mathrm{MBBS}, \mathrm{MD}$,Senior Resident, ${ }^{2} \mathrm{MBBS}, \mathrm{MD}$,Professor, ${ }^{5} \mathrm{MBBS}, \mathrm{MD}(\mathrm{std}), \mathrm{JR}$, \\ Department of Anaesthesiology, J N Medical College, AMU, Aligarh 202002 \\ ${ }^{4}$ MBBS,MD,Senior Resident, Department of Anaesthesiology, Paras Global Hospital, Darbhanga, Bihar \\ Corresponding Author \\ Dr Sarfaraz Ahmad
}

Senior Resident, Department of Anaesthesiology, JNMCH, AMU, Aligarh INDIA

Email: saquasimi2012@gmail.com, Mobile No.: +917417467344

\begin{abstract}
Background: McCoy laryngoscope and many video laryngoscopes are being increasingly used and have a definitive advantage over conventional laryngoscopes in management of anticipated and unanticipated difficult airways. The aim of our study was to compare relative effectiveness of McCoy laryngoscope with king vision video laryngoscope in patients undergoing oral tracheal intubation.
\end{abstract}

Methods: sixty patients of American Society of Anaesthesiologists (ASA) grade I and II, aged 20 - 60 years, posted for elective surgery under general anaesthesia were randomly allocated into Group KVL (King vision video laryngoscope group, $n=30)$ and Group MCC (McCoy group, $n=30)$. The two groups were compared for demographic data, number of intubation attempts, ease of intubation, time to intubation, haemodynamic parameters and any airway trauma.

Results: The demographic data and ASA status was comparable in both the groups. Group KVL had a significantly more first attempts to intubation compared to Group MCC ( $p<0.05)$. The incidence of ease of intubation grade I with King vision video laryngoscope was $93 \%$ while with McCoy laryngoscope was $87 \%$. Th intubation time was less with King vision video laryngoscope as compared to Mc Coy laryngoscope.

There was a transient increase in heart rate and blood pressure after intubation in both the groups which returned back to the baseline within 10 minutes, but rise were less in KVL group. Less airway trauma was noted in the KVL group as compared to MCC groups.

Conclusion: King vision video laryngoscope resulted in better first attempt intubation and less time of intubation than McCoy laryngoscope. Patients in KVL group were more haemodynamicaly stable and less airway trauma were observed.

Keywords: McCoy laryngoscope(MCC), King vision video laryngoscope(KVL), tracheal intubation.

\section{INTRODUCTION}

Airway catastrophe still remains one of the major reasons for mortality and morbidity in anaesthetic practice; so various attempts have been made to modify the laryngoscopes from the conventional Macintosh laryngoscope tothe digital video laryngoscope. Airway problem was the cause of 
over half of anaesthesia-related cardiac arrests in a recent review of adult and paediatric perioperative cardiac arrests ${ }^{[1]}$. Conventional rigid direct laryngoscope aids tracheal intubation in $98.1 \%$ of cases (Rose) $^{[2]}$. However, even the most experienced anaesthesiologistmay encounter difficulties with the rigid laryngoscope and alternativetechniques and equipment for endotracheal intubation (ETI) must bereadily available for the remaining $1.9 \%$ cases.Despite a number of factors and combination of factors have beenidentified to predict difficult intubation, none is capable of identifying allpotentially difficult intubations $^{[3]}$

During difficult intubation, the time required to successfully intubate the trachea may get sufficiently prolonged and leads to oxygen desaturation of the patient. These issues have stimulated in part, in the development ofmultiple novel laryngoscopes, each of which aims to reduce the difficultyof laryngeal visualization, particularly in the setting of the anticipated orunanticipated difficult airway ${ }^{[4]}$ The McCoy laryngoscope is designed to elevate theepiglottis with its hinged tip. This design has twoadvantages compared with the Macintosh laryngoscope;less force is applied during laryngoscopy and stress response to laryngoscopy is reduced, and difficult laryngeal visualisation may be improved by lifting theepiglottis, especially in patients with fixed necks in

neutral position ${ }^{[5-7]}$.

The King Vision Video laryngoscope is a two piece design. It has a reusable monitor that attaches to disposable blades. The King Vision video laryngoscope is the latest in a long series of devices that provide the "perfect view" for intubation via use of video and digital technology. It has two types of bladesone with channel and the other without channel. The display is an organic light emitting diode (OLED) design of surprisingly good clarity and resolution. It is turned on with a single power button on the back of the display and turned off by depressing it for 3 seconds. The device is powered by standard AAA size three batteries. The channeled blade requires minimum of $18 \mathrm{~cm}$ mouth opening while nonchnneled blade requires minimum $13 \mathrm{~cm}$ mouth opening. ${ }^{[8]}$

\section{METHODS}

Following approval from the Institute Ethical Committee (J.N.Medical College,A.M.U., Aligarh, India), patients were randomly divided into 2 groups based on computer generated random number tables. Patients who were intubated using king vision video laryngoscope with channeled blade were labeled as Group (KVL) patients [n=30], Patients who were intubated using Mc Coy laryngoscope with size\# 3 blade were labeled as Group (MCC) patients[n = 30], using ETT no. 7 for female and no. 8 for male. While blinding of the attending laryngoscopist was not possible as the two intubating devices were quite different.Learning curve was achieved by doing 20 intubations using each of the devices on patients prior to start of study.Inclusion criteria were patients of eithersex, aged between 20 to 60 years, weight $50-70 \mathrm{~kg}$, American Society of Anaesthesiologists (ASA) physical status I \& II and who were scheduled to undergo anelective surgical procedure that required general anaesthesiawith oral endotracheal intubation.Signed informed consent was obtained from each patientwho agreed to participate in the study. Exclusion criteria were previous history of multiple/failed intubation,Predicted difficult laryngoscopy except for all class of MP Grades,Any pathology of the oral cavity that may obstruct the insertion of device,Mouth opening $<2.5 \mathrm{~cm}$, potentially full stomach patients (trauma, morbid obesity, pregnancy, history of gastric regurgitation and heart burn) and at risk of oesophageal reflux (hiatus hernia), history of difficult airway, cervical spine injury. In the operation theatre, the patientswere continuously monitored using an electrocardiogram,pulse oximeter, end tidal carbon dioxide, and an automaticnon-invasive blood pressure device. Intravenous line wassecured and ringer lactate was started. 


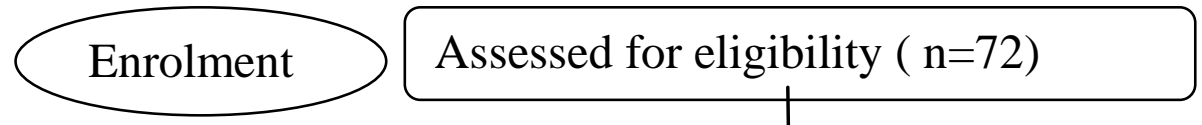

- Excluded ( $\mathrm{n}=12)$

- Not meeting inclusion criteria $(n=8)$

- Declined to participate $(n=4)$

- Other reasons $(\mathrm{n}=0)$

Randomised $\mathrm{n}=60$

- Allocated to inttervention $\mathrm{n}=30$

- Group $(\mathrm{KVL})=$ King vision video laryngoscope added intubation

- Did not receive allocated intervention $\mathrm{n}=0$

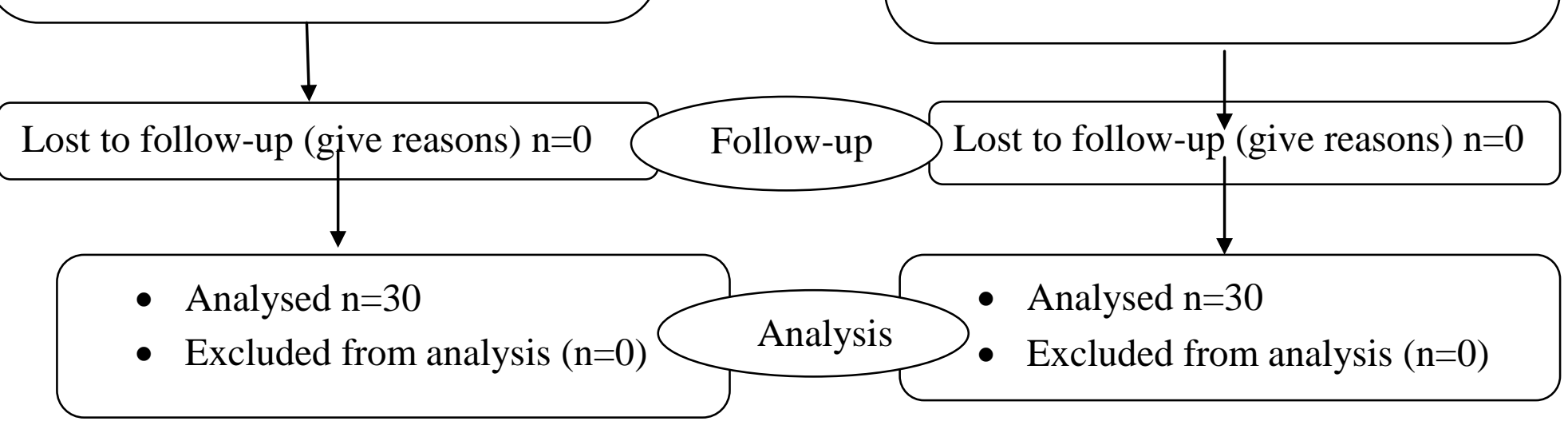

- Allocated to intervention $\mathrm{n}=30$

- $\operatorname{Group}(\mathrm{MCC})=\mathrm{Mc}$ Coy laryngoscope added intubation

- Did not receive allocated intervention $\mathrm{n}=0$

Diagram: Consort flow chart

Each patient was uniformly premedicated with inj. midazolam $0.025 \mathrm{mg} / \mathrm{kg}$, inj.ondansetron $0.15 \mathrm{mg} /$ $\mathrm{kg}$, and inj.fentanyl $2 \mathrm{mcg} / \mathrm{kg}$ of body weight. All drugs were administered intravenously $15 \mathrm{~min}$ prior to transfer of the patient to the operation theatre.A standard anaesthetic technique was used comprising preoxygenation with $100 \% \quad \mathrm{O}_{2}$ for three minutes, induction with inj. Propofol 2 $\mathrm{mg} / \mathrm{kg}$ i.v. neuromuscular blockade was achieved by using inj.vecuroniumbromide $0.1 \mathrm{mg} / \mathrm{kg}$. Laryngoscopy was performed 4 minafter vecuronium administration and intubation was carried out depending on the group to which the patient was assigned.

Once the intubation was complete, lungs weremechanically ventilated during the procedure andanaesthesia was maintained using $60 \%$ nitrous oxide withoxygen and Isoflurane (0.8-1\%). Surgery was allowed to commence only after the collection of the last hemodynamic data at 10 minutes post-intubation.Neuromuscular blockade was maintained with intermittent injections of 
Vecuronium bromide as and when required. Recording oflaryngoscopy \& intubation time was calculated from the time the device was introduced into the mouth till it was removed after endotracheal intubation. The time was measured in seconds by an assistant using a stop watch.Numbers of attempts for successful intubationwas defined as one in which the intubating device was withdrawn from the mouth irrespective of the outcome of the procedure. A maximum of three attempts were allowed. An attempt was consideredunsuccessful if proper placement of endotracheal tube could not be accomplished. Adequate ventilation was confirmed by Et- $\mathrm{CO}_{2}$, bilateral equal air entry on chest auscultation and $\mathrm{SpO}_{2}$ on pulse oximetry.

A 'failed attempt' was defined as removal of the device from the mouth before re-insertion.In between two consecutive attempts patient was ventilated by face mask. After failure of maximum three attempts supraglottic airway device to be used and the case was recorded as 'Failed'one.Grading ease of intubation was done Grade I: When No extrinsic manipulation of the larynx required,Grade II:When External manipulation of the larynx is required,Grade III: Failed intubation. (supraglottic airway device to be used in cases of failed intubation). Changes in heart rate [HR] and Mean Arterial Blood Pressure [MABP] were recorded from the pulse oximeter while BP was recorded using non-invasive manual blood pressure measuring instrument. Immediate preinduction value were recorded and considered as control value. Thereafter, HR \& BP were recorded immediately after laryngoscopy \& intubation and thereafter $3,5 \& 10$ minutes later. MABP $=$ Diastolic $+1 / 3$ Pulse Pressure, Any trauma during intubation was assessedby presence or absence of blood on ETT post extubation. Presence of an unpleasant sensation in the throat [which was not previously present] just prior to discharge from the recovery room and 24 hours later was recorded as evidence of sore throat.

A power analysis was performedto determine the necessary number of patients foreach group based on duration of time of intubation, using an $\alpha=0.05$ and a $\beta=0.2$ for an experimental design incorporating twoequal-sized groups, we estimated that 30 patients would berequired per group. Therefore, 36 patients were enrolled pergroup and a total of 72 patients were included in the study.With atwosided type I error of $5 \%$ and study power at $80 \%$. Thedata was analysed by SPSS for windows (version 17)statistical package (SPSS Inc., Chicago, IL). The datawere expressed as mean \pm standard deviation (SD). Parametric data such as age, weight, time taken for intubation,Mean arterial blood pressure and heart rate values were analyzed using pair wise comparison of the mean values and assessed by unpaired t-test.Non-parametric data such as sex, Mallampati grade, ease of intubation, number of attempts,post-operative blood staining on ETT and sore throat were analyzed using Fisher's exact test.

A P-value of $<0.05$ was considered statistically significant.

\section{RESULT}

The sex distribution was identical in the two groups. In group KVL male and female patients were 10 and 20 respectively. Whereas in group MCC male and female were 13 and 17 respectively.In KVL group 59.99\% and in MCC group $63.32 \%$ were between 20 - 40 years of age. Mean age of the patients were $38.26 \pm 11$.38year and 35.53 \pm 11.74 year in groups KVL and MCC respectively.Most of the patients in the groups were in the normal BMI range of 18.5 - 22.9. Mean BMI in group KVL was $23.19 \pm 2.27$ and in Group MCC was 23.61 2 2.29. In Group KVL $40 \%$ patients were of MP I, $36.66 \%$ were of MP II and $23.33 \%$ patients in MP III \& IV and group MCC, where $56.66 \%$ patients were MP I, $26.66 \%$ patients were MP II and rest being in MP III \& IV.The demographic parameters were comparable in both the study group and $\mathrm{P}$ value was found to be statistically insignificant $(<0.05)$ as shown in table 1.

Of all the patients who were intubated; $93 \%$ of the patients were intubated in single attempt with King Vision video laryngoscope as compared to 


\section{JMSCR Vol||05||Issue||03||Page 19319-19326||March}

$82 \%$ with Mc Coy laryngoscope.However, 7\% patients with King Visionand 18\% withMc Coy required second attempts for intubation. Among the two instruments none had taken more than two attempts for successful intubation. The incidence of ease of intubation grade 1 with King vision video laryngoscope was $93 \%$ and with McCoy laryngoscope was $87 \%$.However; $7 \%$ with King vision, $13 \%$ with Mc Coy had grade 2 ease of intubation. Among the both instrument no failed intubation was done, as shown in the table 2 and figure 1.Statistically significant difference was seen between KVL and MCC group for number of attempts for intubation

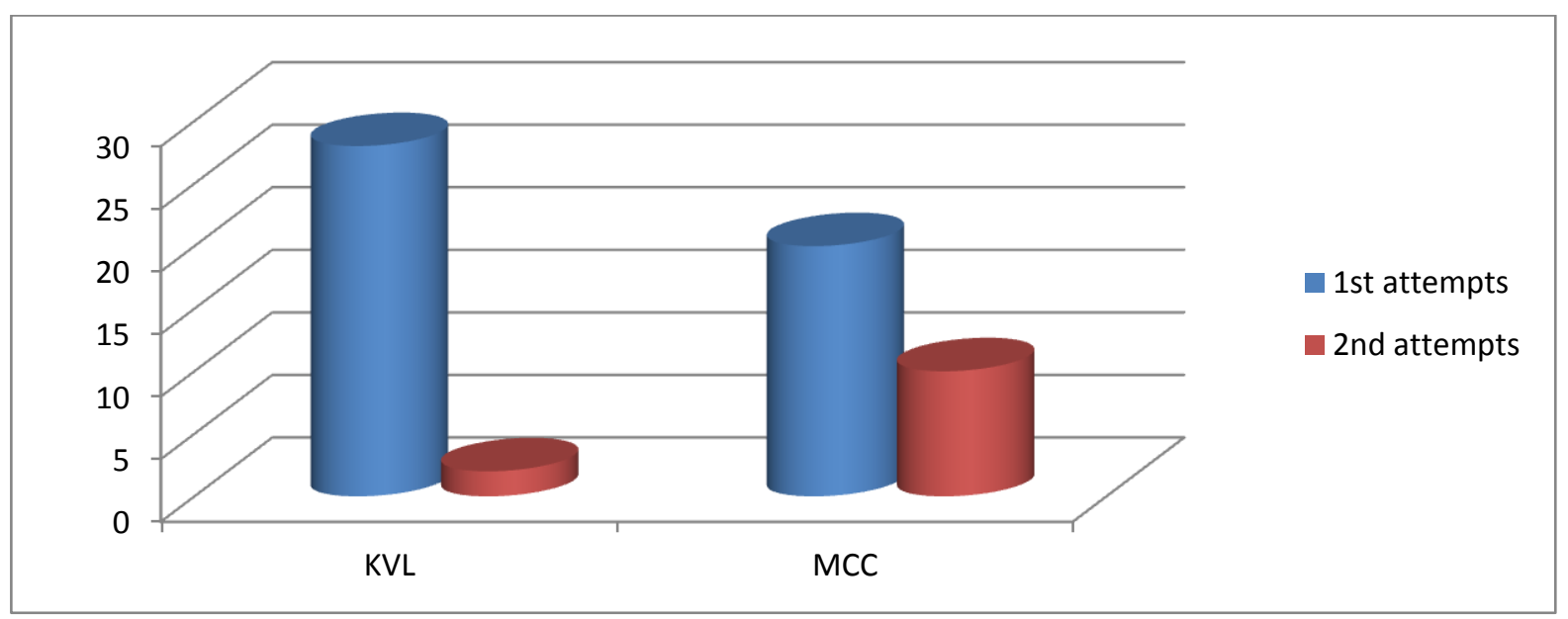

Figure 1: Graphical representation of the number of attempts taken by the three devices to intubate the patients

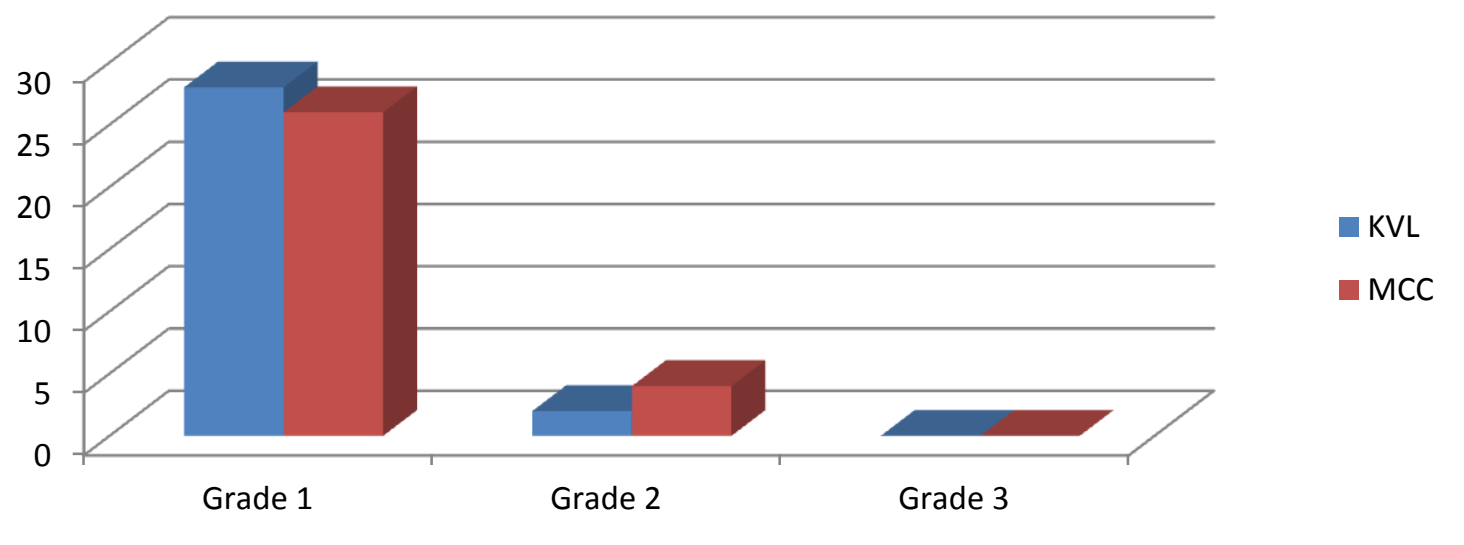

Figure 2: Graphical representation of the relative grading of ease of intubation in the two groups

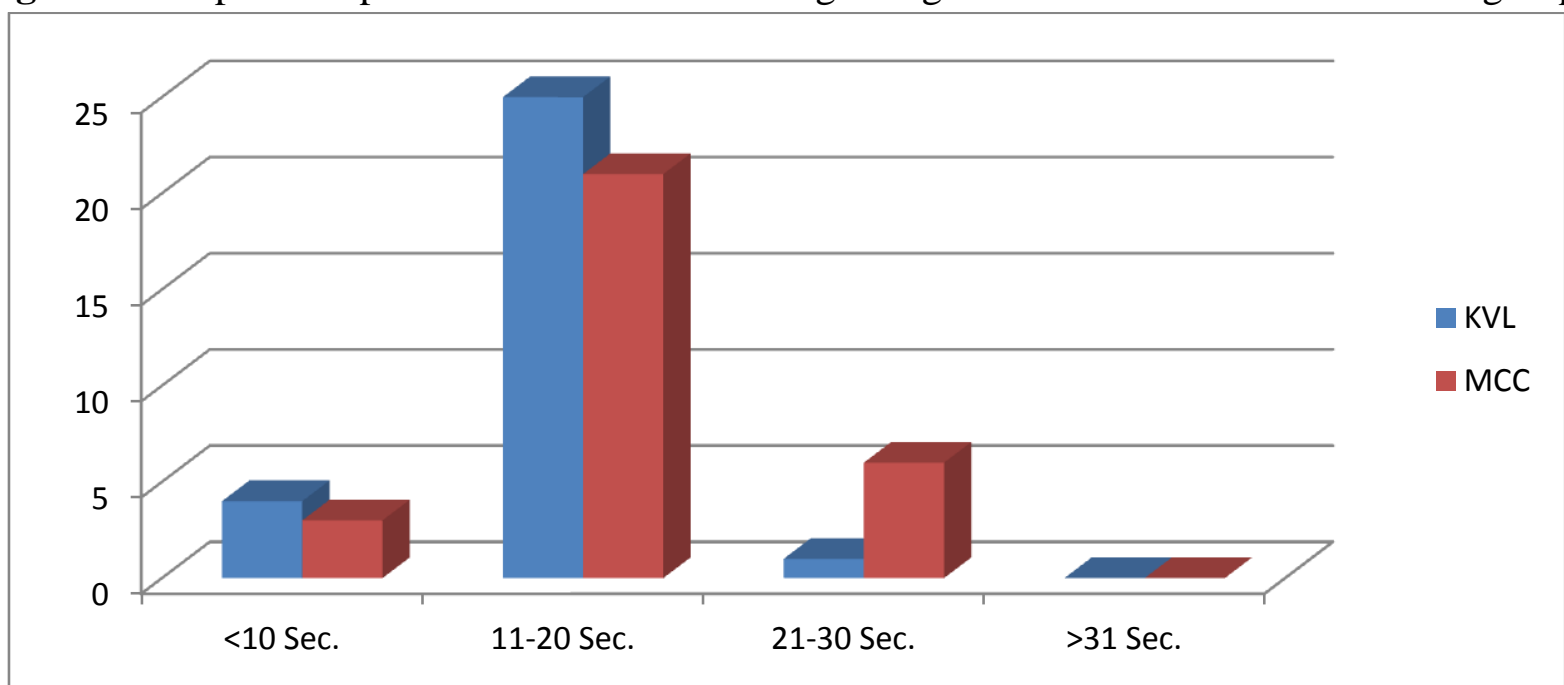

Figure 3: Graphical representation of time taken by the three devices to intubate 
The intubation time was 2.4 sec. less with King vision video laryngoscope $(13.9 \pm 3.16$ sec.) as compared to Mc Coy laryngoscope (16.33 \pm $4.57 \mathrm{sec}$.).

In the two groups; there was a significant rise in heart rate from pre intubation value to 1,3 and 5 minute of post intubation but came down near to preintubation value within 10 minutes of intubation as shown in figure 4. But the post intubation rised in heart was less in KVL group as compared to MCC group.The post intubation rise in mean arterial blood pressure was also significantly less in KVL group as compared to MCC group as shown in figure5.The incidence of post-operative sore throat and blood staining on ETT after extubation were less in KVL group as compared to MCC group.

Table 1: Demographic data and preoperative airway assessment parameters

\begin{tabular}{|l|c|c|c|}
\hline Parameter assessed & $\begin{array}{c}\text { KVL group } \\
(\mathrm{n}=30)\end{array}$ & $\begin{array}{c}\text { MCC group } \\
(\mathrm{n}=30)\end{array}$ & P value \\
\hline Male:female ratio & $10: 20$ & $13: 17$ & 0.5959 \\
\hline $\begin{array}{l}\text { Age (years) } \\
\text { Mean } \pm \text { SD }\end{array}$ & $38.26 \pm 11.38$ & $35.53 \pm 11.74$ & 0.3642 \\
\hline Body mass index $\left(\mathrm{kg} / \mathrm{m}^{2}\right)$ Mean \pm SD & $23.19 \pm 2.27$ & $23.61 \pm 2.29$ & 0.4784 \\
\hline $\begin{array}{l}\text { MP classification } \\
\text { //II/III/IV }\end{array}$ & $12 / 11 / 3 / 4$ & $17 / 8 / 3 / 2$ & 0.383 \\
\hline Weight $(\mathrm{kg}$.$) Mean \pm$ SD & $56.36 \pm 6.67$ & $56.16 \pm 12.27$ & 0.278 \\
\hline
\end{tabular}

Table 2: Parameters for assessment of Intubation difficulty \& Airway Complication

\begin{tabular}{|l|c|c|c|}
\hline Parameter assessed & $\begin{array}{c}\text { KVL group } \\
(\mathrm{n}=30)\end{array}$ & $\begin{array}{c}\text { MCC group } \\
(\mathrm{n}=30)\end{array}$ & P value \\
\hline $\begin{array}{l}\text { Laryngoscopy and intubation time } \\
\text { Mean } \pm \text { SD(sec.) }\end{array}$ & $13.9 \pm 3.16 \mathrm{Sec}$. & $16.33 \pm 4.57 \mathrm{Sec}$. & 0.0603 \\
\hline $\begin{array}{l}\text { No. of attempts } \\
1 / 2\end{array}$ & $28 / 2$ & $20 / 10$ & 0.0106 \\
\hline $\begin{array}{l}\text { Ease of intubation } \\
\text { Grade } 1 / 2 / 3\end{array}$ & $28 / 2 / 0$ & $26 / 4 / 0$ & 0.3354 \\
\hline $\begin{array}{l}\text { Blood Staining } \\
\text { No/Yes }\end{array}$ & $28 / 2$ & $27 / 3$ & 0.50 \\
\hline $\begin{array}{l}\text { Sore Throat } \\
\text { No/Yes }\end{array}$ & $29 / 1$ & $26 / 4$ & 0.1766 \\
\hline
\end{tabular}

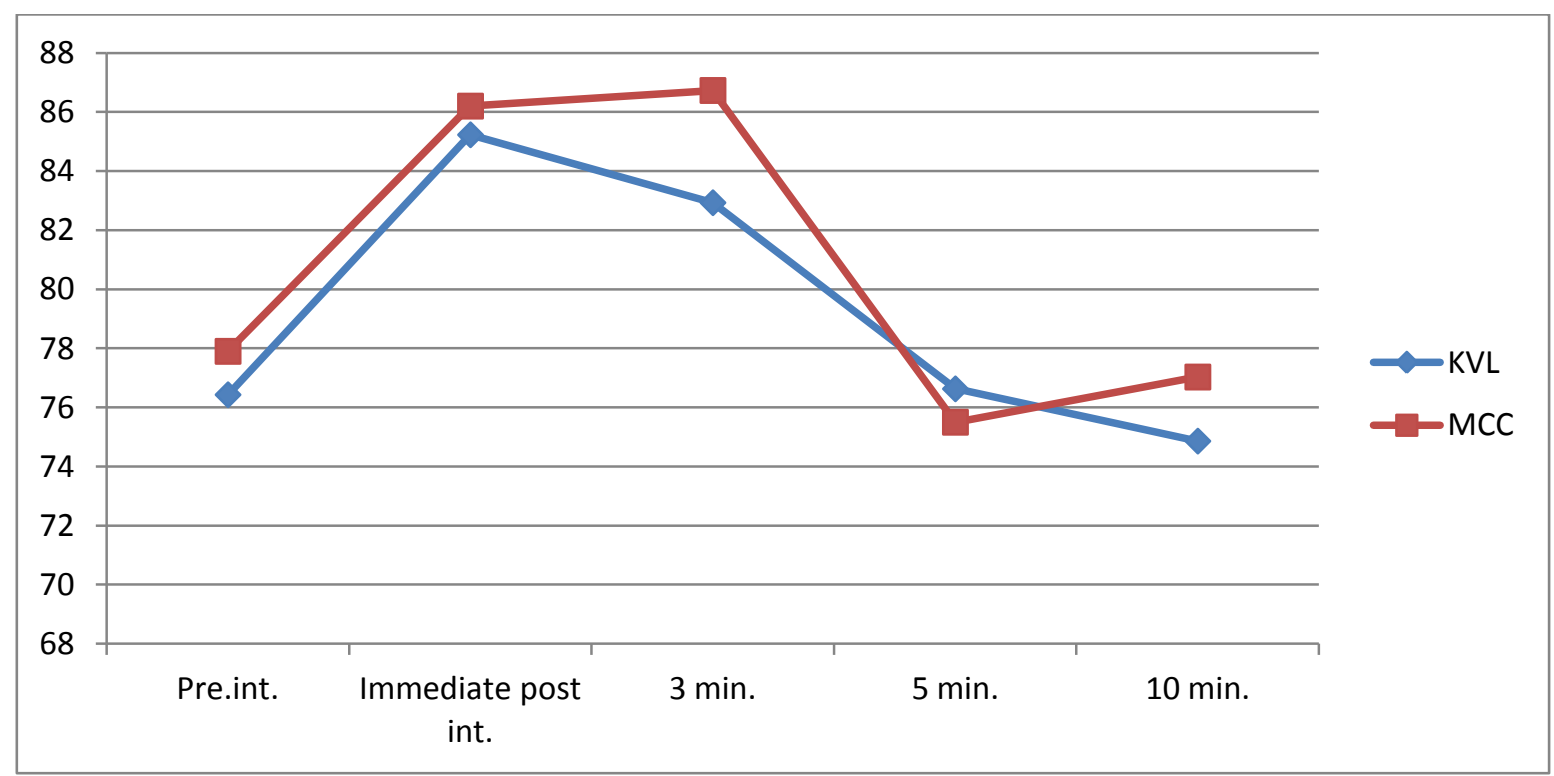

Figure 4: Graphical representation of changes in heart rate at various time intervals in the two groups. 


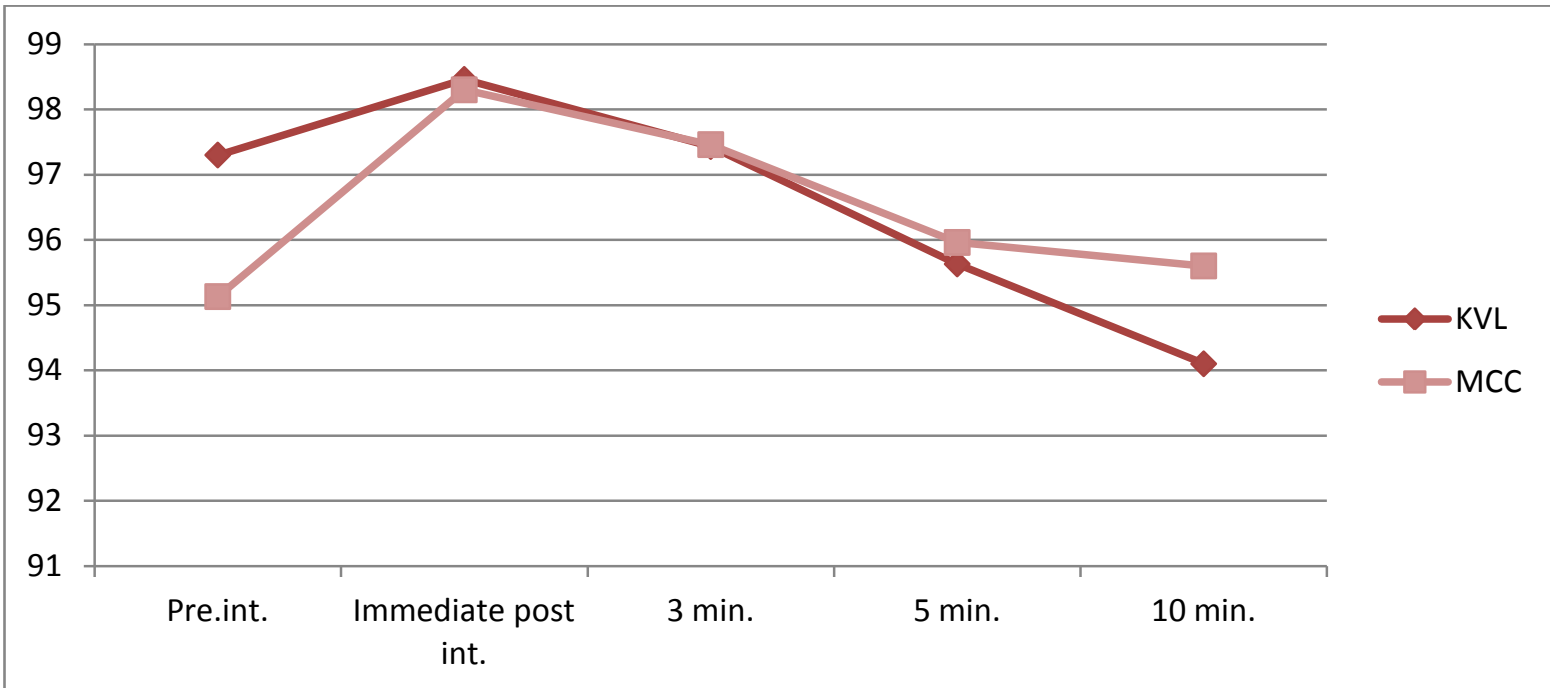

Figure5: Graphical presentation of changes in mean arterial blood pressure at various time intervals in the two groups.

\section{DISCUSSION}

This prospective randomized controlled trial was conducted to assess the utility of the King vision video laryngoscope in normal adult airway. The difficulty of intubation was assessed with numbers of attempts needed and weather external manipulation of larynx was required or not for intubation. In KVL group more numbers of patients were intubated in first attempts as compared to MCC group. External manoeuvres of larynx were applied in more number of cases for intubation with Mc Coy laryngoscope as compared to King vision video laryngoscope. This is due to the clear, bright image of airway anatomy with wider field of vision on the monitor of king vision and also the angulation of the channeled blade make easy hand and eye coordination during intubation and guide the ETT to easily pass through the vocal cord. Also multiple viewer can clearly observe the passage of ETT inside the vocal cord. No other manoeuvres and used of stylet were required to improve the success of intubation in either of the groups. In our study, intubationsuccess was $100 \%$ with both the laryngoscopes; this may be because we did not include patients with anticipated difficult airway and an experienced anaesthetist performed the laryngoscopy.

The time taken for intubation was less with the King vision video laryngoscope (13.9 $\pm 3.16 \mathrm{Sec}$.) than with the Mc Coy laryngoscope $(16.33 \pm 4.57$ $\mathrm{Sec}$ ); however, this difference was found to bestatistically insignificant. The prolonged time of intubation with the Mc Coy laryngoscope was because the field of vision was narrower and smaller, requiring more time to identify the pharyngeal and laryngeal structures to direct the tracheal tube to the glottis opening.

The haemodynamic stress response to laryngoscopy and intubation was found to be less with KVL group as compared to MCC group, since using king vision video laryngoscope; there is no need to adjust the head and neck position \& minimum manipulation of laryngeal structure were required. The detachable nature of king vision monitor and blade make it very easy to introduce the blade without the need of any movement at cervical vertebrae. Mouth opening required for the channelled blade is only about two centimetres due to which the blade could be easily introduced inside mouth of patients by applying only jaw thrust.

The incidence of post-operative sore throat and blood staining on ETT wereless with King vision video laryngoscope, because less manipulation of soft tissue of airway structures was needed during intubation as compared to Mc Coylaryngoscope. There was no incidence of any dental or other trauma in either group.The King vision video laryngoscope has its own learning curve after 
which its success rate and its time taken for successful intubation may further be improved. However, furthercomparative studies with larger sample size in the clinical context particularly in predicted difficult intubation scenarios and in patients with co existing morbidities need to be evaluated.

The main limitation of this study was the potential of observer bias, as it is impossible to blind the anaesthesiologist to the device being used. Another limitation of the study is that we did not study the Cormack-Lehane(C\&L) grading and percentage of glottic opening (POGO) scores.

\section{CONCLUSION}

King vision video laryngoscope is better in visualising larynx in neutral position of patients head and neck with high success rates. King vision is better than Mc Coy laryngoscope with respect to the ease of intubation, number of first attempts of successful intubation, haemodynamic stress response to intubation and post operative pharyngeal morbidity.It should be used either as primary airway device or should be immediately available in patients with predicted difficult intubation, or as a rescue device in unanticipated difficult intubation.

\section{BIBLIOGRAPHY}

1. Braz LG, Modolo NS, do Nascimento P Jr, Bruschi BA, Castiglia YM, Ganem EM, et al. Perioperative cardiac arrest: a study of 53, 718 anaesthetics over 9 year from a Brazilian teaching hospital. Br J Anaesth 2006; 96:569-75.

2. Rose DK, Cohen MM.The Airway: problems and predictions in 18,500 patients. Can J Anaesth 1994;41:372-83.

3. Tse JC, Rimm EB, Hussain A. Predicting difficult endotracheal intubation in surgical patients scheduled for general anesthesia: a prospective blind study. AnesthAnalg 1995;81:254-8.

4. Chisholm DG, Calder I.Experience with the McCoy laryngoscope in difficult laryngoscopy. Anaesthesia 1997;52:906-8.
5. McCoy EP, Mirakhur RK, Rafferty C, Bunting H, Austin BA. A comparison of the forces exerted during laryngoscopy. The Macintosh versus the McCoy blade. Anaesthesia 1996; 51: 912-5.

6. McCoy EP, Mirakhur RK, McCloskey BV. A comparison of the stress response to laryngoscopy. The Macintosh versus the McCoy blade. Anaesthesia 1995; 50: 9436.

7. McCoy EP, Mirakhur RK. The levering laryngoscope.Anaesthesia 1993; 48: 5169.

8. El-Tahan M, Doyle DJ, Khidr AM, Hassieb AG. Case Report: Double lumen tube insertion in a morbidly obese patient through the non-channelled blade of the King Vision $\left({ }^{\mathrm{TM}}\right)$ videolaryngoscope. F1000Res. 2014;3:129. eCollection 2014. 